\title{
Structural evaluation updating based on quality control and proof loads
}

\author{
Mohamed Saad Abbadi, Nouzha Lamdouar \\ Laboratoire Génie Civil du CEDOC «Sciences et Techniques pour l'Ingénieur», Ecole Mohammedia d'Ingénieurs, \\ Université Mohammed V, Rabat, Maroc
}

\begin{abstract}
In a context of limited available resources, the structural evaluation of bridges is important to avoid the high costs of replacement and repair. As a rational evaluation criterion, the reliability of structures based on probabilistic theories provides an accurate estimate of the current strength and the remaining life time. It also represents an effective approach for analysing structural reliability under uncertainties in parameter estimates during the service life of designed and existing structures, especially during the construction. Where new information concerning the actual bridge conditions is available, which is unknown in the design phase. The certificates of material properties, measurements of actual bridge geometry, collection load data, and results of proof load testing are the major resources of this information. The extra information unknown in the design phase could be used to reduce some uncertainties related to the bridge member resistance and load parameters entering the evaluation process. The aim of this study is twofold: (a) taking into account the uncertainties ofstrength parameters, by presenting some approaches for the efficient inclusion of quality control and proof loads in the structural reliability assessment process.The results of these approaches reveals the actual safety margins in the structure and permits to avoid either unnecessary reinforcement operations or unjustified reduced load limits.
\end{abstract}

\section{INTRODUCTION}

The social and economic losses because of the high costs of replacement and repair operations raises the awareness to improve the resilience and sustainability of infrastructures, especially in a context of limited available resources.

Design codes presents safety margins that can be excessive regarding existing bridge assessment, which some characteristics can be defined with more accuracy. The assessment of the structures is relevant as it allow to avoid unnecessarily conservative measures adopted in the design, and reduce some uncertainties related to the bridge member resistance and load parameters.

In particular, some uncertainties can be reduced in the phase post-construction and it's convenient to update the real state of the structure.

Special attention is given to the reliability updating using the two major extra information available after achievement, which are the results of the certificates of materials properties and proof loads.

Proof loading may provide additional knowledge about resistance. For example, a structure which survives a certain load may be considered as more reliable than one which has never been exposed to such a load.

Quality control of material properties during the construction process can be used as a first update of the partial factors used in the design. This should be carried out within the framework of a probabilistic reliability theory, in accordance with the margin of safety intended in the Eurocode.

As a rational evaluation criterion, the reliability of structures based on probabilistic theories provide an accurate estimate of the current strength and the remaining life time. It also represent an effective approach for analysing structural reliability under uncertainties in parameter estimates during the service life of both designed and existing structures.

The present paper intends to provide a semiprobabilistic format in verifications of existing reinforced concrete Bridges, in accordance with the target reliability intended in the Eurocode. Thus, this approach is in order to achieve either of the following goals:

- For a given reliability level, design new partial factors. 
- For a given partial factors, estimate the real reliability level.

\section{METHODOLOGY:}

\subsection{Overview on the Assessment methods of reliability:}

Depending on the approach to reliability, there are three levels of performance evaluation:

Level 1 consider deterministic approach, the safety margin is introduced through central safety factor (ratio of design and resistance factors). It's simple of use but Inadequate for considering variability of input parameters and generally leads to excessive design. The general formula is expressed in terms of permissible stress as:

$\sigma \leq \sigma_{a d m}=\frac{\sigma_{r u p t}}{K}$

Where $\sigma$ is the actual stress on the structure, $\sigma_{a d m}$ is the admissible limit of stress, depending on the properties of materials and the level of safety preconized, $K$ is the central safety factor and $\sigma_{\text {rupt }}$ is the ultimate tensile strength.

Level 2, defined as semi-probabilistic approach, consist on the verification of a criterion involving design values of strength $R$ and Load $S$, noted $R_{d}$ and $S_{d}$, Applied in conjunction with the concept of limit states (ultimate, serviceability, fatigue).

$R_{d}=\frac{1}{\gamma_{R d}} R\left(\ldots, \frac{f_{i}}{\gamma_{f i}}, \ldots\right) \geq S_{d}=\gamma_{S_{d}} S\left(\ldots, \gamma_{F_{j}} F_{j}, \ldots\right)(2)$

$f_{i}, F_{j}$ Correspond to characteristic values associated to strength and load variables. $\gamma_{f i}, \gamma_{F_{j}}$ are the related partial safety factors for these variables while $\gamma_{S_{d}}, \gamma_{R d}$ represent the partial factors covering the modeling uncertainties.

Level 3 require a full reliability analysis to quantify the probability of failure of the structure under various loading scenarios. The acceptance criterion is defined in terms of the closeness of the actual reliability index to the optimum reliability level. Then the basic equation is expressed in terms of probabilities:

$P_{f}=P(R<S) \leq P_{f 0}$

Where $P_{f}$ is the probability of failure, $R$ is resistance, $S$ is action, $P_{f 0}$ is the target probability.

The use of the probabilistic techniques of level 3 for structural assessment is basically not common in civil engineering. But it can be very valuable in the assessment of existing structures, because such approaches can handle uncertainties in a more efficient manner than a semi-probabilistic format as introduced in the Eurocode.
And permits to efficiently and correctly manipulate information obtained from measurements and inspections.

\subsection{Partial factor calibration:}

The partial factor $\gamma_{R}$ of material resistance $\mathrm{R}$ is defined, in accordance to Eurocode, as the fraction of its characteristic value $R_{K}$ and the design value $R_{d}$, as bellow:

$\gamma_{R}=\frac{R_{K}}{R_{d}}$

The characteristic value $R_{K}$ of a resistance variable $\mathrm{R}$ is defined as its $5 \%$ fractile. Thus, in the case of a resistance variable $\mathrm{R}$ having a normal distribution, then the characteristic value is given as:

$R_{K}=\mu_{R}-1,645 * \sigma_{R}=\mu_{R}\left(1-1,645 * V_{R}\right)$

Where $V_{R}$ is the coefficient of variation of the resistance $\mu_{R}$ is the mean value of the performance function $\sigma_{R}$ is itsthe standard deviation

The design value $R_{d}$ of $\mathrm{R}$ can be estimated using the expression:

$R_{d}=\mu_{R}-\alpha_{R} * \beta * \sigma_{R}=\mu_{R}\left(1-\alpha_{R} * \beta * V_{R}\right)$

Where $\alpha_{R}$ is the sensitivity factor of $\mathrm{R}$, taken in the Eurocode equal to 0,8 .

The partial factor $\gamma_{R}$ for a normal distribution of $\mathrm{R}$ can be assessed as:

$\gamma_{R}=\frac{\left(1-1,645 * V_{R}\right)}{\left(1-\alpha_{R} * \beta * V_{R}\right)}$

Assuming a lognormal distribution of $\mathrm{R}$ its characteristic value $R_{k}$ can be determined using approximate equation:

$R_{K}=\mu_{R} * \exp \left(-1,645 * V_{R}\right)$

Similarly the design value $R_{d}$ is approximated as:

$R_{d}=\mu_{R} * \exp \left(-\alpha_{R} * \beta * V_{R}\right)$

Taking into account equations (14) and (15) it follows that the partial factor $\gamma_{R}$ for lognormal distribution can be assessed as:

$\gamma_{R}=\exp \left(-1,645 * V_{R}\right) / \exp \left(-\alpha_{R} * \beta * V_{R}\right)$

\subsection{Truncated method for Updating by proof load:}


The truncated method consist on updating the probability density function (PDF) of resistance, after experiencing a load proof with a convincing results in term of deflection and safety. Then, it shows that structural resistance

$\mathrm{R}>R_{\text {test }}$, where $R_{\text {test }}$ is the resistance corresponding to the test load applied, then with the truncated method, the $f_{R}(x)$ is updated and transferred into $f_{R, u p}(x)$.

The PDF is described before experiencing the proof load as follow:

$\int_{-\infty}^{+\infty} f_{R}(x) d x=F_{R}\left(R_{\text {test }}\right)+\int_{R_{\text {test }}}^{+\infty} f_{R}(x) d x$

After testing successfully the structure under a proof load, the truncated distribution function is expressed as follow:

$\int_{R_{\text {test }}}^{+\infty} f_{R, u p}(x) d x=1$

From the two equations above, the updated PDF is:

$f_{R, u p}(x)= \begin{cases}\frac{f_{R}(x)}{1-F_{R}\left(R_{\text {test }}\right)}, & x \geq R_{\text {test }} \\ 0, & x<R_{\text {test }}\end{cases}$

The updated mean value and variance are respectively:

$$
\begin{aligned}
& \mu_{R, u p}=\int_{-\infty}^{+\infty} x f_{R, u p}(x) d x=\frac{\mu_{R}-\int_{-\infty}^{R_{\text {test }}} x f_{R}(x) d x}{1-F_{R}\left(R_{\text {test }}\right)} \\
& V_{R, \text { up }}=\frac{V_{R}-\left(\mu_{R, u p}-\mu_{R}\right)^{2}-\int_{-\infty}^{R_{\text {test }}}\left(x-\mu_{R, u p}\right)^{2} f_{R}(x) d x}{1-F_{R}\left(R_{\text {test }}\right)}
\end{aligned}
$$

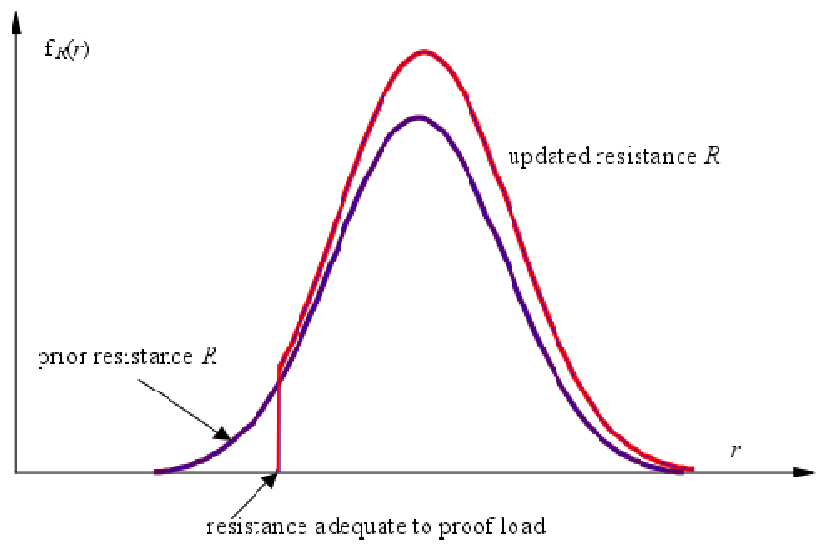

Fig 1.Probability density function of resistance prior to proof loading and after surviving the proof loading.

Loading the structure can be considered as a test, the load may be a service load or an exceptional load. In both cases the proof load level $R_{\text {test }}$ can be considered as the lower bound on $f_{R}$, and the updating by truncated method can be applied as well as in a case of proof load.

\subsection{Updating proof level}

This section consider calibration of intensities of proof loads for updated resistance, based on a target reliability index beta

The reliability index of proof load is expressed as:

$\beta=\frac{\mu_{R}-Q_{t e s t}}{\sigma_{R}}$

Where:

As the proof load can be fixe with accuracy, its value can be taken as deterministic.

After updating resistance, and preserving the same reliability level, we can consider the expression below:

$\beta=\frac{\mu_{R, u p}-Q_{t e s t, u p}}{\sigma_{R}, u p}$

From the eq and the updated proof level is calculated as follow:

$\frac{Q_{\text {test }, \text { up }}}{Q_{\text {test }}}=\frac{\mu_{R, u p}-\beta * \sigma_{R, u p}}{\mu_{R}-\beta * \sigma_{R}}=\frac{\mu_{R, u p}}{\mu_{R}}\left(\frac{1-\beta * V_{R, u p}}{1-\beta * V_{R}}\right)$

\section{RESULTS AND DISCUSSIONS:}

\subsection{Quality control on material properties:}

A sample of $n=120$ concrete compressive strength measurement, obtained during the construction, is to be used to assess the characteristic value of the concrete strength $f_{c k}$.

Tab 1. Results of compressive strength measurements

\begin{tabular}{|l|l|||l|l||l|l|||l|l||l|l|}
\hline$n$ & $f_{c}$ & $n$ & $f_{c}$ & $n$ & $f_{c}$ & $n$ & $f_{c}$ & $n$ & $f_{c}$ \\
\hline 1 & 35.1 & 25 & 27.6 & 49 & 38.6 & 73 & 35 & 97 & 32.6 \\
\hline 2 & 35.6 & 26 & 30.1 & 50 & 39 & 74 & 34.2 & 98 & 32.7 \\
\hline 3 & 36.2 & 27 & 30.4 & 51 & 40.4 & 75 & 37.1 & 99 & 32.9 \\
\hline 4 & 36.6 & 28 & 30.8 & 52 & 40.7 & 76 & 38.2 & 100 & 33.1 \\
\hline 5 & 37.2 & 29 & 31.3 & 53 & 50.6 & 77 & 38.8 & 101 & 33.6 \\
\hline 6 & 35.4 & 30 & 32.5 & 54 & 29.9 & 78 & 42.7 & 102 & 34.1 \\
\hline 7 & 34.1 & 31 & 31.8 & 55 & 30.6 & 79 & 46 & 103 & 33.9 \\
\hline 8 & 37 & 32 & 34.4 & 56 & 30.3 & 80 & 28.6 & 104 & 34.7 \\
\hline 9 & 36.8 & 33 & 33.3 & 57 & 31 & 81 & 30.4 & 105 & 34.8 \\
\hline 10 & 35.3 & 34 & 37.8 & 58 & 30.8 & 82 & 30.2 & 106 & 35.6 \\
\hline
\end{tabular}




\begin{tabular}{|c|c|c|c|c|c|c|c|c|c|}
\hline 11 & 33.2 & 35 & 37.1 & 59 & 32 & 83 & 30.8 & 107 & 34.9 \\
\hline 12 & 33.4 & 36 & 40.7 & 60 & 32.8 & 84 & 30.8 & 108 & 36.4 \\
\hline 13 & 32.8 & 37 & 38.4 & 61 & 32.4 & 85 & 30.9 & 109 & 37.4 \\
\hline 14 & 32.6 & 38 & 26.9 & 62 & 33.9 & 86 & 31.2 & 110 & 37.5 \\
\hline 15 & 33.8 & 39 & 30 & 63 & 33.2 & 87 & 31.3 & 111 & 37.4 \\
\hline 16 & 33.7 & 40 & 30.5 & 64 & 34.6 & 88 & 31.3 & 112 & 38.3 \\
\hline 17 & 34.1 & 41 & 31.5 & 65 & 34.9 & 89 & 31.7 & 113 & 37.9 \\
\hline 18 & 34.3 & 42 & 31.9 & 66 & 38.3 & 90 & 31.5 & 114 & 38.6 \\
\hline 19 & 35.4 & 43 & 32.3 & 67 & 36.4 & 91 & 31.9 & 115 & 39.8 \\
\hline 20 & 34.9 & 44 & 33.2 & 68 & 28.2 & $\overline{92}$ & 31.8 & 116 & 40.3 \\
\hline 21 & 36.1 & 45 & 34.4 & 69 & 31.9 & 93 & 31.9 & 117 & 42.4 \\
\hline 22 & 36.3 & 46 & 36.3 & 70 & 31.1 & 94 & 32.2 & 118 & 43.1 \\
\hline 23 & 35.8 & 47 & 37.4 & 71 & 32.6 & 95 & 32.1 & 119 & 42.6 \\
\hline 24 & 25.9 & 48 & 38 & 72 & 33.7 & 96 & 32.4 & 120 & 49.4 \\
\hline
\end{tabular}

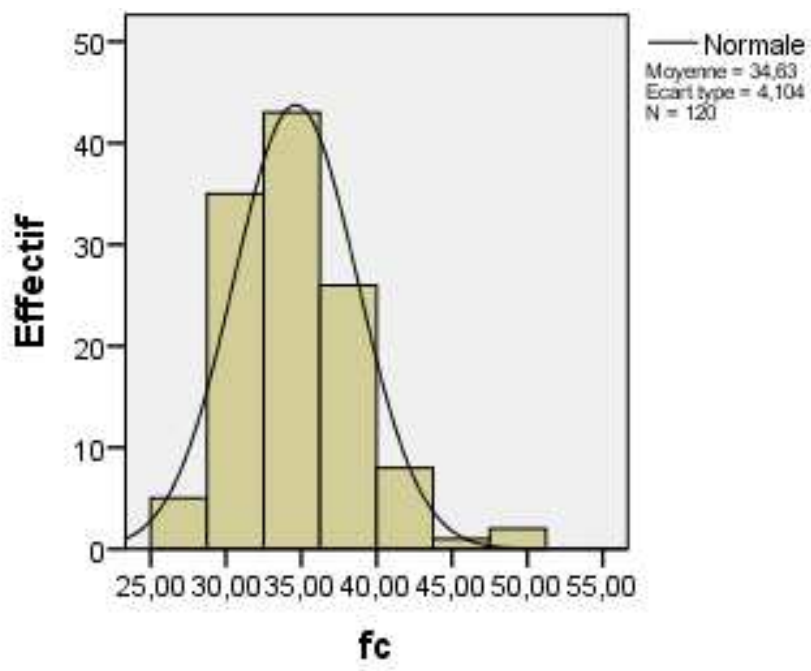

Fig 2.Histogram of compressive strength of concrete showing normal distribution fit

A sample of $n=40$ yield tensile measurement, obtained during the construction, is to be used to assess the characteristic value of elasticity limit
Tab 2. Results of tensile yield measurements

\begin{tabular}{|c|c|c|c|c|c|c|c|c|c|}
\hline$n$ & $f_{y}$ & $n$ & $f_{y}$ & $n$ & $\overline{f_{y}}$ & $n$ & $\overline{f_{y}}$ & $n$ & $\overline{f_{y}}$ \\
\hline 1 & 502.1 & 9 & 506.2 & 17 & 507.3 & 25 & 509.4 & 33 & 509.5 \\
\hline 2 & 511.6 & \begin{tabular}{|l|}
10 \\
\end{tabular} & 511.7 & 18 & 506.8 & 26 & 502.9 & 34 & 508.1 \\
\hline 3 & 513.2 & \begin{tabular}{|l|}
11 \\
\end{tabular} & 525.3 & 19 & 527.4 & 27 & 524.5 & 35 & 521.6 \\
\hline 4 & 518.7 & 12 & 519.8 & 20 & 517.9 & 28 & 519.1 & 36 & 522.2 \\
\hline 5 & 523.3 & 13 & 524.4 & 21 & 527.5 & 29 & 534.6 & 37 & 533.7 \\
\hline 6 & 531.8 & \begin{tabular}{|l|}
14 \\
\end{tabular} & 530.9 & 22 & 529.1 & 30 & 528.2 & 38 & 529.3 \\
\hline 7 & 529.4 & 15 & 527.5 & 23 & 534.6 & 31 & 520.7 & 39 & 511.8 \\
\hline 8 & 504.9 & 16 & 521.1 & 24 & 534.2 & 32 & 537.3 & 40 & 542.8 \\
\hline
\end{tabular}

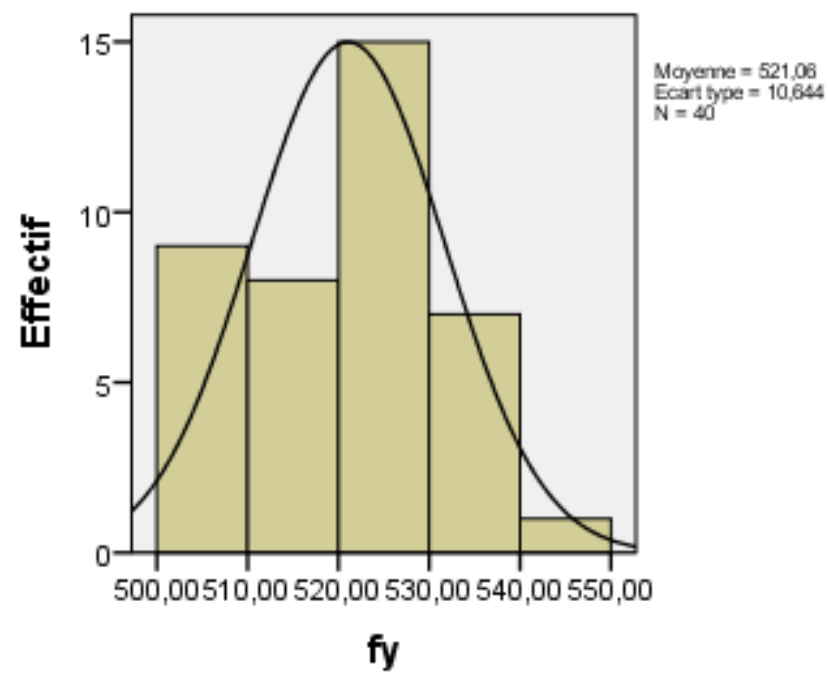

Fig 3. Histogram of yield tensile showing normal distribution fit

The following table resume the statistical results of concrete and yield characteristics:

Tab 3.Statistical results of concrete and yield measurements 


\begin{tabular}{|l|l|l|}
\hline & Concrete & yield \\
\hline Mean (MPa) & 34.63 & 521.06 \\
\hline $\begin{array}{l}\text { Standard } \\
\text { deviation (MPa) }\end{array}$ & 4.10 & 10.64 \\
\hline $\begin{array}{l}\text { Coefficient of } \\
\text { variation }\end{array}$ & 0.12 & 0.02 \\
\hline $\begin{array}{l}\text { Characteristic } \\
\text { value (MPa) }\end{array}$ & 27.88 & 503.92 \\
\hline $\begin{array}{l}\text { Design value } \\
\text { (MPa) }\end{array}$ & 22.15 & 489.38 \\
\hline $\begin{array}{l}\text { Updated Partial } \\
\text { factor }\end{array}$ & 1.26 & 1.03 \\
\hline $\begin{array}{l}\text { Initial partial } \\
\text { factor }\end{array}$ & 1.50 & \\
\hline
\end{tabular}

\subsection{Updating reliabilityof a slab:}

Considering a mid-cross section of simply supported slab having the span of $12 \mathrm{~m}$, exposed to a bending Moment $M_{E L U}$, a simple drawing of the cross-section is indicated below, including stress distribution diagrams in the compressive concrete zone (rectangular and triangular) Further, the concrete $\mathrm{C} 25 / 30$ having the characteristic strength $f_{c k}=25 \mathrm{MPa}$ and reinforcement bars S 500 having the characteristic strength $f_{y k}=500 \mathrm{MPa}$

The following table resume the main characteristics of the slab:

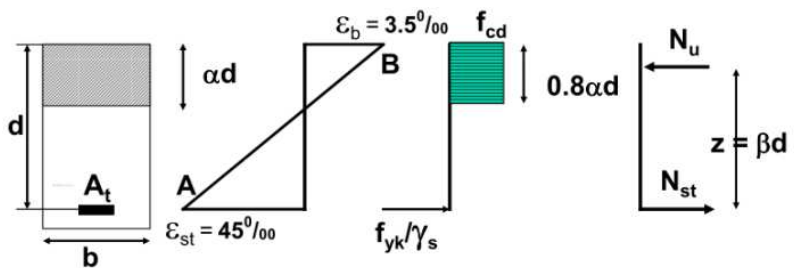

Fig 4. Stress distribution in the reinforced concrete slab

When the rectangular stress diagram is assumed the following equilibrium conditions can be written:

$N_{u}=0,8 f_{c d} \alpha d b$

$M_{u}=N_{u} \beta d=N_{u}(1-0,4 \alpha) d$

$M_{u}=0,8 b d^{2} f_{c d}(1-0,4 \alpha)$

Where d denotes the effective depth, $\alpha d$ the depth of the neutral axis, $\beta$ the distance between $N_{u}$ et $N_{s t}$, b the width of the slab, $A_{s}$ the area of the reinforcement, $f_{c d}$ the concrete strength and $f_{y d}$ the reinforcement strength (yield point).

$\mu=\frac{M_{E L U}}{b d^{2} f_{c d}}=0,8 \alpha(1-0,4 \alpha)$

$$
\begin{aligned}
& \alpha=1,25\left(1-(1-2 \mu)^{\frac{1}{2}}\right) \\
& A_{s}=0,8 \alpha b d \frac{f_{c d}}{f_{y d}} \\
& M_{R}=(1-0,4 \alpha) d f_{y d} A_{s} \\
& M_{R}=\left(1-0,5\left(1-\left(1-2 * \frac{M_{E L U}}{b d^{2}} \frac{\gamma_{c}}{f_{c k}}\right)^{0.5}\right)\right) * d * \frac{f_{y k}}{\gamma_{s}} * A_{s}
\end{aligned}
$$

The criterion $\sigma_{c}<0,6 f_{c k}$ is not determinant, as well as the crack opening and the fatigue.

After linearizing $M_{R}$ about the design point values, we obtain:

\begin{tabular}{|c|c|c|}
\hline & Design & Post construction \\
\hline$f_{c k}[\mathrm{MPa}]$ & 25 & 27,88 \\
\hline$f_{y k}[\mathrm{MPa}]$ & 500 & 503,92 \\
\hline$A_{S}\left[\mathrm{~cm}^{2}\right]$ & 62,63 & 64,80 \\
\hline$\mu_{M_{R}}[$ MN.m] & 1,562 & 1,649 \\
\hline$\sigma_{M_{R}}[\mathrm{MN} . \mathrm{m}]$ & $144,02 * 10^{-3}$ & $39,47 * 10^{-3}$ \\
\hline$\beta$ & 1,99 & 9,475 \\
\hline
\end{tabular}

$$
\begin{gathered}
M_{R} \approx-1,736+7,13 * 10^{-3} * f_{c}+3,12 * 10^{-3} * f_{y}+249 \\
* 10^{-4} * A_{s}
\end{gathered}
$$

Tab 4. Characteristics of the slab

Tab 5. Reliability index before and after updating

\begin{tabular}{|l|c|l|l|l|}
\hline Variable & Symbol & Mean & $\begin{array}{l}\text { Standard } \\
\text { deviation }\end{array}$ & $\begin{array}{l}\text { Distribution } \\
\text { function }\end{array}$ \\
\hline Span & $\mathrm{L}[\mathrm{m}]$ & 12 & 0 & Deterministic \\
\hline Load & $\begin{array}{c}M_{E L U} \\
{[\mathrm{MN} \cdot \mathrm{m}]}\end{array}$ & 1,275 & 0 & Deterministic \\
\hline width & $\mathrm{b}[\mathrm{m}]$ & 1 & 0 & Deterministic \\
\hline depth & $\mathrm{d}[\mathrm{m}]$ & 0,55 & 0 & Deterministic \\
\hline $\begin{array}{l}\text { Concrete } \\
\text { strenght }\end{array}$ & $\begin{array}{c}f_{c} \\
{[\mathrm{MPa}]}\end{array}$ & 34,63 & 4,10 & Normal \\
\hline Yield strenght & $\begin{array}{c}f_{y} \\
{[\mathrm{MPa}]}\end{array}$ & 521,06 & 10,64 & Normal \\
\hline $\begin{array}{l}\text { Area of } \\
\text { reinforcement }\end{array}$ & $\begin{array}{c}A_{s} \\
{\left[\mathrm{~cm}^{2}\right]}\end{array}$ & 64,80 & 0 & Deterministic \\
\hline
\end{tabular}

\subsection{Truncated method for Updating by proof load:}

A simulation, based on the equations (14) and (15) show the updated mean, by proof load, of the resistance. A comparison of two cases is considered: update based on actualized mean and standard deviation after quality control consideration, and update based on the design characteristics. 


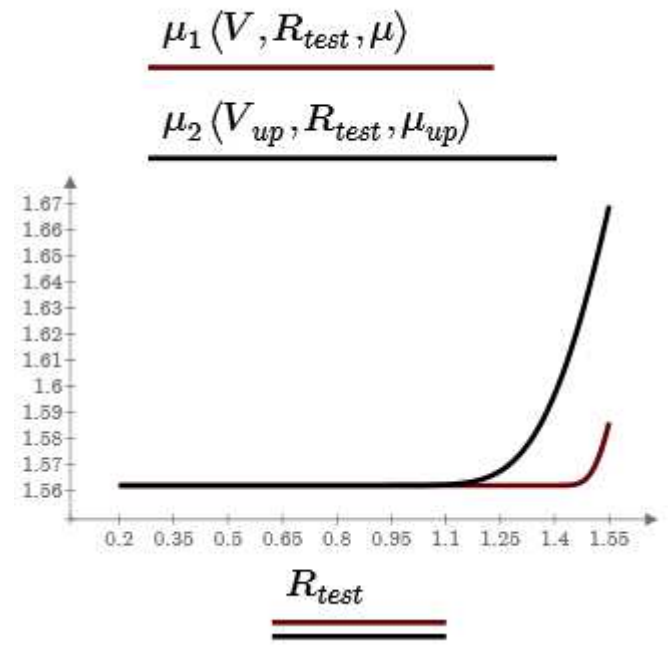

Fig 5.Updated mean v. proof load level in both cases with and without quality control consideration

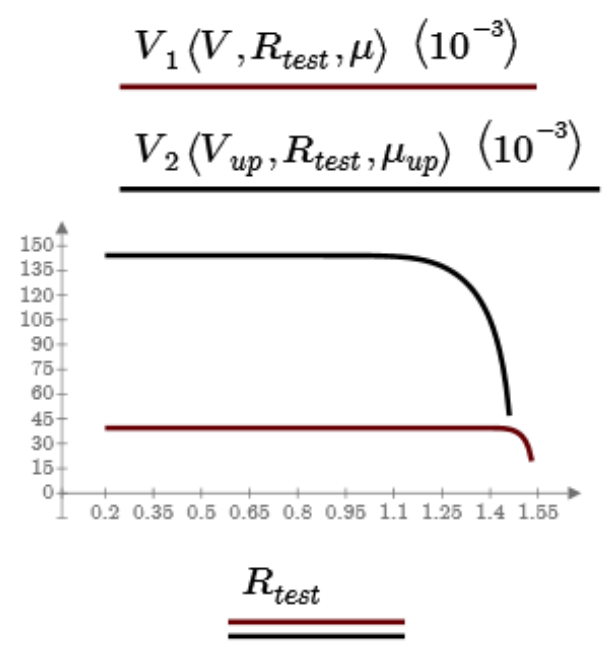

Fig 6.Updated standard deviation v. proof load level in both cases with and without quality control consideration

Structural reliability can be significantly improved by proof loading especially in the cases when $V_{u p}$ are smaller than $V$.

\subsection{Updating proof level}

Maintaining the same reliability level, the proof load can be updating, in accordance with the equation (18) we obtain:

$\frac{Q_{\text {test,up }}}{Q_{\text {test }}}=1,23$

It means that the proof load level can be raised about $23 \%$, and staying with the same safety margin.

\section{Conclusions and perspectives:}

Structural evaluation updating have been investigated, taking into account the two extra-information acquired in the construction phase: results of quality control of material properties and proof loads.

The update with the results of quality control gives a better description of the distribution of the variables related to the material properties, permitting a calibration of the partial factors and an assessment of the reliability index.

The update with proof load, consisting on the fact that a successful proof load test demonstrates that the resistance of a bridge is greater than the proof load, reduces uncertainty in the bridge resistance and so increases the bridge reliability, the truncated method constitute a great approach to embody this update, and combined with the update by control quality, gives better results.

As a main results, partial factors of concrete and yield where optimized about $16 \%$ and $10 \%$. The reliability index was greatly improved after update by both quality control and proof load.

Another main outcome is the adjustment of proof load level, in accordance with the first update by quality control, as the reliability level remain the same.

In the light of these results,many promising areas of improvement can be conducted, it starts with updating partial factors of actions, based on more accurate analysis of traffic and dead load of the structure, the relationship between the components of a structural system and how a reliability approaches can be established in a context of correlated variables. Also, the reliability of exceptional load passing can be improved, revealing the actual safety margin and permits to avoid either unnecessary reinforcement operations or unjustified reduced load limits.

And finally, prior exceptional loads may be treated as an uncertain proof load, since the fact that a bridge had survived the exceptional trafficking means that the bridge resistance is greater than the load effect.

\section{References}

1. T. Shan Lin, A. S.Nowak. Proof Loading and Structural Reliability (1984).

2. W.B Hall, M.Tsai. Load Testing, Structural Reliability and Test Evaluation (1989)

3. M.H.Faber, D.V.Val, M.G.Stewart. Proof load testing for bridge assessment and upgrading (2000).

4. C.Cremona, B.Poulin, A.Colas. Calibration of partial safety factors for the assessment of existing bridges (2013).

5. R.Rackwitz, K.Schrupp. Quality Control, Proof Testing and Structural Reliability (1984).

6. M.Sykora, M.Holicky, J.Markova. Verification of existing reinforced concrete bridges using the semiprobabilistic approach (2013).

7. L.Yuefei, L.Dagang, F.Xueping. Reliability updating and prediction of bridge structures based on proof loads and monitored data (2014) 